\title{
A colleague to remember
}

\author{
Hendrik Emons ${ }^{1}$
}

Published online: 11 May 2016

(c) Springer-Verlag Berlin Heidelberg 2016

A few weeks ago the ever-increasing stream of communication items arriving at my virtual desk contained a message which changed my usual way of dealing with them for a while. I took some time to remember-Paul de Bièvre.

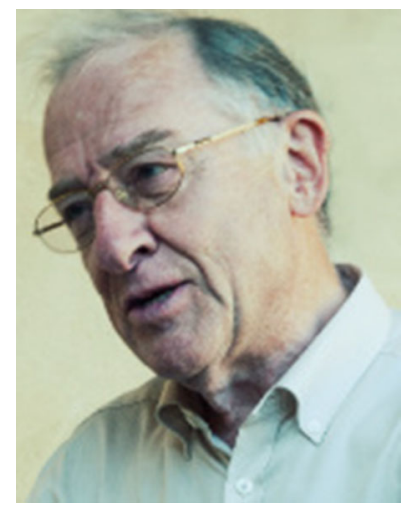

Paul de Bièvre (1933-2016)

I realized that I have forgotten when I met Paul de Bièvre for the first time. But I remember well how enthusiastically he was talking during one of my visits to the European Commission's Institute for Reference Materials and Measurements (IRMM) more than 20 years ago. It was about interlaboratory comparisons based on independently established reference values and concepts for a very precise and commonly to be used terminology on measurements in chemistry.

Hendrik Emons

JRC-IRMM-ACQUAL@ec.europa.eu

1 Geel, Belgium

Since then I had very regular contacts with Paul. Not primarily at IRMM, despite his appointments there as Head of the Isotope Measurement Unit until 1998 and as Advisor to the Director until 2002 as well as his visits on IRMM's Open Days and anniversary celebrations. I have rather discussed with him at conferences and meetings all over the world or at his home in Kasterlee (relatively close to the IRMM).

For me Paul was one of the most prominent ambassadors for metrology in chemistry. He devoted his professional life, which definitely did not stop after his official retirement from the European Commission (did he retire at all?) to promote the comparability of measurement results and the common understanding of metrology among scientists. For that purpose he was a global traveler, missing only very few countries of the world, and an invited speaker at many conferences and seminars. Paul was always keen to stipulate what he called "clear thinking.' This gained him in my eyes the label 'Mister Terminology,' in the combination of creating and promoting terms as well as underlying concepts. His contributions to the development of the International Vocabulary of Metrology (VIM) are certainly the most visible, but not the only signs of these efforts.

When I joined committees or organizations such as CCQM, ISO/REMCO, Eurachem or CITAC, Paul had been already there. He had truly a 'founding mentality'! Indeed, Paul has been recognized as one of the founding fathers of CIPM's Committee on Metrology in Chemistry (CCQM), as co-founder of Eurachem and CITAC, and he was one of the founding editors of this journal Accreditation and Quality Assurance (ACQUAL). Many of his ACQUAL editorials, later published as 'Paul's Columns,' were taken up by colleagues as education material or as stimulus for advancing metrological concepts and approaches further. They initiated also controversial debates and the 
publication of opposite opinions, as even demonstrated with an example in this issue of ACQUAL. This is very much in the spirit of Paul's way of working and exercising an influence on our reflections.

Remembering Paul de Bièvre includes for me also a reflection on the role and impact of individual scientists. The sceneries and boundary conditions have certainly changed over the last 20-30 years. Now it seems unlikely that one scientist would be able to serve actively in so many bodies in parallel as Paul did or that one could travel so much when still being in duty. However, I believe that we continue to need scientists with a critical mind, who stick to their ideas and concepts until those are either being proven wrong or being replaced by more advanced thinking. We need individuals who are not shy in asking critical questions, who do not avoid also lengthy discussions about more fundamental issues and who make us thinking again and again about our own concepts and scientific approaches. Therefore, Paul will not only be missed by his family but also by his scientific colleagues and the metrology-inchemistry community at large.

Hendrik Emons

Editor-in-Chief 